\title{
HUGH WILSON: um capitalista britânico na Bahia oitocentista
}

\author{
HUGH WILSON: a Capitalist British Nineteenth-century Bahia
}

\author{
Marcos Guedes Vaz Sampaio ${ }^{1}$ \\ Felipe Amorim Campos ${ }^{2}$
}

Resumo: a Inglaterra, nação pioneira na Revolução Industrial, exerceu a hegemonia sobre o sistema internacional no decurso do século XIX, expandindo suas relações econômicas. O Brasil foi destino importante de capitais ingleses no transcurso deste período. A Bahia, enquanto uma das províncias mais expressivas do império brasileiro oitocentista, também recebeu aporte substancial de inversões britânicas, distribuídas em vários setores. Dentre eles, o setor de transportes se destacou pelo volume dos investimentos e pela significativa presença inglesa, notadamente nas ferrovias e na navegação a vapor. O presente artigo visa empreender um olhar mais atento à participação inglesa neste setor, destacando a atuação do engenheiro e capitalista Hugh Wilson.

Palavras-chave: Ingleses; Bahia; investimentos; transportes

Abstract: England, the pioneer nation of the Industrial Revolution, exercised hegemony over the international system during the nineteenth century, expanding their economic relations. Brazil was important destination of British capital in the intervening period. Bahia, one of the most important provinces of the Brazilian nineteenthcentury empire, also received substantial inflow of British investments, distributed in various sectors. Among them, the transportation sector is highlighted by the volume of investments and the significant English presence, notably in the railways and steam navigation. This article aims to take a closer look at the English participation in this industry, highlighting the performance of the engineer and capitalist Hugh Wilson.

Keywords: English; Bahia; investments: transports.

(recebido em 25 de julho de 2012; aprovado em 19 de outubro de 2012)

\section{Introdução}

A Inglaterra ${ }^{3}$ foi a nação pioneira da Revolução Industrial consolidando um ciclo de hegemonia sobre o sistema econômico internacional que atravessou o século XIX, encontrando seu ocaso no transcurso do século XX através da ascensão da economia norteamericana (ARRIGHI, 2006). O pioneirismo industrialista britânico favoreceu a ampliação de suas relações comerciais, permitindo a construção de um modelo onde as principais nações gravitavam em torno do seu centro mercantil e financeiro. A superação desse quadro se deu, de maneira gradativa, no decorrer do período oitocentista, à medida que as nações iam promovendo a transformação da composição de suas economias internas, via industrialização. Chang (2004) conta que algumas nações, dentre elas a Alemanha, a Suíça e a França chegaram a utilizar de espionagem industrial para acelerar seu desenvolvimento. A

1 Doutor em História Econômica (USP), economista (UFBA), professor adjunto do Instituto de Humanidades Artes e Ciências Prof. Milton Santos (IHAC) e do Curso de Mestrado em Economia da Universidade Federal da Bahia (UFBA).E-mails: mgvsampaio@hotmail.com/marcos.sampaio@ufba.br.

2 Graduando no Bacharelado Interdisciplinar em Humanidades no Instituto de Humanidades Artes e Ciências Prof. Milton Santos (IHAC) da Universidade Federal da Bahia (UFBA) e bolsista PIBIC. E-mail: famorimcampos@gmail.com

3 Inglaterra e Grã-Bretanha, assim como ingleses e britânicos, serão tratados como sinônimos neste trabalho, como normalmente os autores assim procedem. Exemplo importante neste sentido é a obra clássica de Gilberto Freyre, “Ingleses no Brasil”. (Nota dos autores) 
amplificação das relações econômicas mundiais a partir da Inglaterra, por sua vez, revela o domínio do capital britânico sobre as demais nações, em processo de industrialização. Hobsbawm (1986, p. 127) assim se referiu à força da penetração inglesa no cenário econômico mundial:

\begin{abstract}
Um país adiantado, em processo de industrialização, de início necessitava da GrãBretanha, uma vez que - pelo menos nos estágios preliminares - beneficiava-se do recurso à fonte ímpar de capital, maquinaria e técnica que era a Grã-Bretanha, e às vezes não tinha outra alternativa. Encontramos repetidamente no resto da Europa as primeiras fábricas ou oficinas mecânicas iniciadas por algum inglês, as primeiras maquinas nacionais copiadas deste ou daquele projeto original britânico [...] É inevitável verificarmos que as primeiras estradas de ferro tenham sido construídas por empreiteiros britânicos, usando locomotivas, trilhos, pessoal técnico e capital provenientes da Grã-Bretanha.
\end{abstract}

A infante nação brasileira se inseriu de maneira periférica dentro do sistema mundial, orquestrado pela pujança dos capitais ingleses e das teias de relações amalgamadas pela emergência do capital industrial britânico. Taxas preferenciais de comércio e ambiente permissivo à alocação de recursos ingleses em território nacional se traduziram em aumento da dependência em relação à Grã-Bretanha que dominou o comércio exterior brasileiro e liderou os investimentos na modernização da infra-estrutura interna. $\mathrm{O}$ desenvolvimento das ferrovias, navegação a vapor, telégrafo, iluminação pública, estradas macadamizadas (método Mac Adam, de origem inglesa) podem ser elencados como exemplos da penetração substantiva dos britânicos no Brasil. Batista Jr. (1980, p. 204) apontou que, enquanto a Inglaterra praticava o protecionismo, sendo a nação mais poderosa do mundo, o Brasil adotava uma política liberal, reflexo de sua submissão aos interesses britânicos:

[...] as principais exportações brasileiras eram sistematicamente excluídas do mercado britânico por tarifas fixadas em nível proibitivo. O próprio texto dos tratados negava de modo explícito a possibilidade de permitir a entrada na Inglaterra de exportações brasileiras que concorressem com produtos das colônias britânicas. Enquanto o Brasil era forçado por esses acordos comerciais a seguir uma política tarifária liberal, a Inglaterra manteve uma orientação em que predominava o protecionismo até a década de 1840, com barreiras tarifárias protegendo da concorrência estrangeira não só as colônias e o setor agrícola, como também alguns setores mais atrasados da indústria.

A Bahia, enquanto província do Império do Brasil, foi destino de uma parte razoável das inversões inglesas na América Latina. Recursos esses, assim como no conjunto da economia brasileira, majoritariamente, destinados aos setores adjacentes ao vetor dinâmico da economia regional. Os capitais ingleses contribuíram para a modernização da estrutura produtiva baiana por meio da implantação da navegação a vapor e das ferrovias, dentre outros setores. 
O processo de modernização, no entanto, foi capitaneado pelo setor de transportes destacando-se, a princípio, a navegação a vapor. Tecnologia mais avançada do mundo no segmento de transportes, a navegação movida a maquinário a vapor precedeu o desenvolvimento das ferrovias e permitiu aproximar as diversas regiões do mundo, ampliando as relações comerciais e fortalecendo o espectro de ação inglês dentro do sistema econômico internacional.

As iniciativas domésticas de modernização, quando ocorriam, esbarravam nas dificuldades inerentes a um modelo econômico de base escravista, centrado na monocultura do açúcar, na mentalidade conservadora das elites rurais e no frágil mercado interno. Movimentos mais consistentes de modernização da estrutura produtiva baiana somente surgiram após o fim do tráfico de escravos, a partir de 1850 (PEDRÃO, 2000). O vanguardismo da navegação a vapor, enquanto transporte regular organizado por uma empresa, embora tenha iniciado em 1839, o mote principal de sua inauguração parece ter relação muito mais forte com a instabilidade política do período regencial do que com motivações econômicas (SAMPAIO, 2006).

A eclosão de insurreições em diversas partes do território nacional motivou o governo regencial a buscar mecanismos visando reforçar a centralidade do poder monárquico. Sob este aspecto, o estímulo ao surgimento de companhias regionais de navegação a vapor como auxiliares de uma companhia maior, de cunho nacional, favoreceria a consolidação de um projeto nacionalista de integração territorial, dando sentido de unidade ao país, ao mesmo tempo em que reforçava, por meio do envio célere de tropas e comunicações do governo central, a centralização administrativa do Brasil (EL-KAREH, 2002; SAMPAIO, 2006; SAMPAIO, 2008).

A Província da Bahia experimentou um movimento modernizante direcionado, prioritariamente, ao setor dos transportes, devido a motivações políticas e econômicas. A partir da década de 1850, com a abolição do tráfico de escravos, os capitais outrora empregados no comércio de cativos se voltaram para outros segmentos, impulsionando a urbanização e o desenvolvimento de setores da indústria e do comércio e serviços, ampliando o escopo modernizador da economia baiana. A partir do próximo tópico, o processo de modernização vivenciado pela Província da Bahia será analisado de maneira mais detida, destacando-se o setor de transportes e a presença inglesa neste processo.

\section{O fim do tráfico de escravos e a ampliação das relações econômicas entre o Brasil e a Inglaterra}


As relações diplomáticas entre o Brasil e a Inglaterra estremeceram durante a primeira metade do século XIX devido às resistências brasileiras quanto à adoção de medidas de abolição do tráfico de escravos e do sistema escravista, propriamente dito. O recrudescimento das atitudes enérgicas dos britânicos contra o Brasil derivava do evidente retardo das autoridades nacionais no sentido de extinguir o tráfico de cativos.

A evolução das relações econômicas entre Brasil e Inglaterra no decurso do oitocentos teve um ponto forte de inflexão a partir do fim do tráfico de escravos em 1850, momento em que as tensões se arrefeceram e os laços econômicos e políticos se fortaleceram, renovando o ambiente para os negócios entre agentes dos dois países. Prado Jr. (1986, p. 154) assim se referiu a este momento:

\begin{abstract}
A abolição do tráfico terá ainda outro efeito indireto: põe termo ao longo conflito com a Inglaterra; e das relações políticas que então se estabelecem com aquele país, resultará novo afluxo de suas iniciativas e capitais para o Brasil. A expansão dos negócios ingleses retomará seu ritmo normal e progressivo, que declinara muito nos anos anteriores de atritos e desentendimentos.
\end{abstract}

Em poucos anos os britânicos predominavam em diversas atividades produtivas no Brasil. Estavam presentes no setor financeiro, na infra-estrutura e também no controle de atividades exportadoras (SEPLANTEC, 1978). Segundo Graham (1973) foi principalmente no campo dos investimentos diretos que os britânicos exerceram sua influência, destacadamente na construção de ferrovias. Em 1880 havia 11 companhias britânicas de estradas de ferro e, dez anos depois, já somavam 25.

O interesse dos investidores britânicos se adequou ao interesse do Império brasileiro, que buscava a modernização, mas não possuía meios para realizá-la sem capitais e conhecimentos técnicos já consolidados na vida dos britânicos. O Brasil vivia uma situação de dependência externa, e foi assim que se modernizou. Corroborando esta afirmação, Graham (1973, p. 59) aponta que:

\footnotetext{
Os brasileiros foram atacados cedo pela febre de assentar trilhos de aço através do país, e os portadores desta infecção foram os engenheiros e os empresários britânicos. Foi um inglês quem idealizou as leis básicas para as estradas de ferro brasileiras.
}

Este inglês era Thomas Cochrane, que foi o primeiro a elaborar projetos de ferrovias para o Brasil, com base nos conhecimentos adquiridos na sua pátria. Como resultado de suas pressões, o governo imperial aceitou a idéia de que não seria possível realizar tal empreendimento no Brasil sem o apoio do Estado. Se por um lado o Brasil não reunia 
condições para implementar tais mudanças, tampouco o capital privado investiria sem garantias oferecidas pelo governo.

Sendo assim, em 26 de junho de 1852 veio a lei que concedia juros de $5 \%$ sobre o capital investido na construção de ferrovias. Esta foi a primeira medida tomada pelo governo brasileiro para incentivar tais empreendimentos. Carletto (1979, p. 17) menciona que desde a implantação de ferrovias na Europa e América do Norte, surgiu no Brasil: “...uma conscientização de que a estrada de ferro seria um elemento de vital importância para o desenvolvimento que o país estava a reclamar”.

A política imperial objetivava fomentar a unidade territorial, encurtando distâncias entre as regiões do país e para isto as ferrovias eram fundamentais. A navegação fluvial já era utilizada neste sentido, mas necessitando de uma complementação por vias terrestres, cuja melhor opção era o investimento na construção de vias férreas. Fazia-se necessário, portanto, criar oportunidades para atrair o capital estrangeiro.

O momento, no entanto, não era favorável devido à instabilidade do mercado em Londres, por causa da Guerra da Criméia. Diante desse quadro, o governo buscou tornar a implantação de ferrovias mais atrativa, aumentando de $5 \%$ para $7 \%$ a garantia de juros sobre 0 capital investido nas estradas de ferro (CARLETTO, 1979, p. 15). As dificuldades internas de recursos para empreender a modernização necessária ao progresso do país se traduziram na dependência do capital estrangeiro, como atesta Prado Jr (1986, p. 195):

Com as iniciativas privadas colaborará o Estado, arrastado no movimento; e
sobretudo o capital estrangeiro (o inglês em particular),ávido de captar em seu
benefício as atividades de uma jovem nação em pleno florescimento. Os grandes
empreendimentos industriais (estradas de ferro...), embora indispensáveis e condição
essencial de qualquer realização posterior, estavam ainda, na maior parte, além das
possibilidades do capital privado indígena que apenas ensaiava seus primeiros
passos. O capital estrangeiro e o Estado tomam-nos a seu cargo. Este último, aliás,
no mais das vezes, não servirá senão de empresário, levantando empréstimos no
exterior para realizar os empreendimentos. Em outros casos, como se deu na maior
parte das estradas de ferro, intervirá apenas estimulando o capital estrangeiro com a
concessão de garantia de juros.

Essa dependência do capital externo se traduziu no recrudescimento da presença britânica no cotidiano da sociedade brasileira oitocentista. De fato era tão marcante que um ministro norte-americano assim se referiu sobre a força da dominação inglesa no Brasil, conforme relatou Rodrigues (1953, p. 80):

[...] A Grã-Bretanha fornece ao Brasil os seus navios a vapor e a vela, calça-lhe e drena-lhe as ruas, ilumina-lhe a gás as cidades, constrói-lhe as ferrovias, explora-lhe as minas, é o seu banqueiro, levanta-lhe as linhas telegráficas, transporta-lhe as 
malas postais, constrói-lhe as docas, motores, vagões, numa palavra - veste e faz tudo, menos alimentar o povo brasileiro.

A incontestável presença inglesa na economia brasileira se refletia sobremaneira sobre a Província da Bahia. O setor de transportes, pelo pioneirismo inglês e pujança de sua indústria e evolução tecnológica, simbolizava a força desse domínio. A navegação a vapor na Bahia foi inaugurada por ingleses antes do fim do tráfico de escravos, mais precisamente no ano de 1839. O capital inglês adentrava a vida econômica da Bahia no transcurso do século XIX, principalmente na segunda metade. Alguns ingleses, especificamente, se sobressaíram mais do que outros nos envolvimentos com a vida econômica e social da província. Dentre eles, um cidadão inglês merece um estudo mais detalhado em função de variadas referências ao seu nome em diversos documentos encontrados no Arquivo Público do Estado da Bahia (APEB). Nos próximos tópicos serão apresentados os resultados de um esforço investigativo em buscar informações sobre este capitalista britânico que viveu na Bahia na segunda metade do oitocentos e que teve participação ativa nos projetos modernizadores internos.

\section{Hugh Wilson e a navegação a vapor na Bahia oitocentista}

Os ingleses, em virtude do seu vanguardismo na era industrial, acumularam experiência e conhecimento técnico nos setores mais avançados do século XIX, destacadamente o segmento de transportes com a navegação a vapor e as ferrovias. Inúmeros britânicos migraram para diversos países com o objetivo de montar suas próprias empresas, se associarem a capitalistas estrangeiros ou trabalharem como mão-de-obra qualificada em empreendimentos que representavam a fronteira da evolução técnica da época.

No Brasil e, em particular, na Bahia, isto não foi diferente, registrando-se em terras baianas a chegada de inúmeros ingleses para se incorporarem ao trabalho técnico de maior qualificação ou para cargos mais importantes dentro das companhias domésticas ou mesmo criando empresas ou se associando a elas.

Os ingleses que chegavam à Bahia para trabalhar como maquinistas ou em outras funções relacionadas ao desenvolvimento da metalurgia, da navegação, ferrovias, telégrafo, iluminação pública, dentre outros setores modernizantes também treinavam a mão-de-obra local, o que permitiu reduzir a dependência desse trabalhador estrangeiro mais qualificado ao longo do tempo. É o que aponta a tabela abaixo, revelando a diminuição no número de maquinistas estrangeiros registrados na Bahia na segunda metade do século XIX, mais precisamente entre os anos de 1860 e 1892. 
Tabela 1. Registro de maquinistas na Província da Bahia (1860-1892)

\begin{tabular}{l|l|l|l|l|l}
\hline Ano & Estrangeiros & Nacionais & Ano & Estrangeiros & Nacionais \\
\hline 1860 & 2 & 2 & 1877 & 2 & 8 \\
\hline 1862 & 10 & 1 & 1878 & 2 & 6 \\
\hline 1863 & 2 & 0 & 1879 & 3 & 13 \\
\hline 1864 & 3 & 2 & 1880 & 0 & 4 \\
\hline 1865 & 7 & 10 & 1881 & 4 & 3 \\
\hline 1866 & 7 & 2 & 1882 & 3 & 1 \\
\hline 1867 & 2 & 1 & 1883 & 0 & 8 \\
\hline 1868 & 0 & 2 & 1884 & 8 & 8 \\
\hline 1869 & 0 & 1 & 1885 & 2 & 15 \\
\hline 1870 & 3 & 3 & 1886 & 0 & 6 \\
\hline 1871 & 5 & 6 & 1887 & 0 & 11 \\
\hline 1872 & 0 & 3 & 1888 & 4 & 17 \\
\hline 1873 & 8 & 1 & 1889 & 5 & 9 \\
\hline 1874 & 1 & 6 & 1890 & 2 & 7 \\
\hline 1875 & 1 & 3 & 1891 & 4 & 14 \\
\hline 1876 & 0 & 9 & 1892 & 0 & 37 \\
\hline Total (1) & 51 & 52 & Total (2) & 39 & 167 \\
\hline
\end{tabular}

Fonte: SAMPAIO, 2006.

Os dados apresentados revelam que dos 309 registros de maquinistas encontrados, 90 pertenciam a estrangeiros e 219 a nacionais. Pode-se perceber que, no decorrer dos anos, o número de estrangeiros registrados como maquinistas, gradualmente, se reduziu, passando de, aproximadamente 50\%, na primeira metade do período (1860-1876), para cerca de $19 \%$ na segunda metade do período estudado (1877-1892). Não foi possível encontrar documentos que identificassem a nacionalidade dos estrangeiros, no entanto, o expressivo domínio britânico sobre a economia mundial e a brasileira em particular, estendendo-se, naturalmente, este domínio sobre o fator tecnológico, permite inferir que a maioria destes estrangeiros era de nacionalidade britânica.

Uma informação que corrobora esta ilação é oriunda de dois documentos de registros de maquinistas que trabalharam na Companhia Bahiana de Navegação a Vapor, fundada pelos ingleses no final da primeira metade do século XIX. Estes documentos apontam que entre 1860 e 1889 foram registrados 55 maquinistas, sendo 32 estrangeiros e 23 nacionais, revelando que, ao menos na Companhia Bahiana, 58,2\% dos maquinistas registrados no período eram estrangeiros (SAMPAIO, 2006, p.292). Durante toda a pesquisa que resultou na tese de doutoramento sobre a Companhia Bahiana de Navegação a Vapor não foi encontrada nenhuma evidência de estrangeiros que não fossem de origem britânica trabalhando na empresa.

Outro estudo, desenvolvido em parceria com o professor Fernando Pedrão, sobre a presença inglesa no setor metalúrgico da Província da Bahia no transcurso do período 
oitocentista, revelou que 53,33\% das empresas deste setor na Bahia foram constituídas por britânicos entre 1819 e 1889 (PEDRÃO, SAMPAIO, 2002, p. 51). Este número reforça a ilação de que, provavelmente, a maioria dos maquinistas registrados na Bahia durante a segunda metade do oitocentos era de origem britânica.

Neste contexto, de presença marcante dos britânicos no cotidiano da economia baiana durante o século XIX, que a atuação do engenheiro e empresário Hugh Wilson mereceu destaque, por sua atuação no desenvolvimento do sistema de transportes na Província da Bahia. A história de Hugh Wilson na Bahia está fortemente atrelada ao segmento dos transportes, sua modernização e ampliação. A pesquisa mostra que ele foi um empreendedor que participou de diversos projetos de integração territorial na Província da Bahia, destacando-se como um dos principais capitalistas da região no período.

A Província da Bahia enfrentava a precariedade das comunicações entre suas regiões em virtude do péssimo estado de conservação das estradas carroçáveis e da insuficiência do transporte fluvial e marítimo, restrito a poucas localidades. Diante desse quadro, algumas regiões eram mais integradas ao comércio com outras províncias (MATTOSO, 1986, p.458), o que prejudicava o desenvolvimento baiano.

A balança comercial da Província foi superavitária entre 1865 e 1880, tendo como principais produtos de exportação o fumo, o café e o açúcar (CALMON, 1979). Entretanto o comércio poderia ser ainda mais vantajoso se fossem melhoradas as vias que ligavam as regiões produtoras. Neste sentido o Recôncavo baiano se destacava como região de importante dinamismo econômico e maior integração, dada a proximidade entre suas principais vilas e a capital da Província. Exercendo função de entreposto comercial das mercadorias que iam para o porto de Salvador, três localidades se destacavam nessa função: Nazaré, Santo Amaro e Cachoeira. Nestas duas últimas o capitalista Hugh Wilson esteve mais presente, diretamente relacionado ao processo de integração das regiões por meio de estradas de ferro.

Antes de se envolver com o setor ferroviário, no entanto, Hugh Wilson participou ativamente do projeto de aquisição e ampliação da Companhia Bahiana de Navegação a Vapor, quando readquirida pelos ingleses em 1862. Empresa que havia sido fundada por ingleses na Bahia ainda na primeira metade do século XIX, mais precisamente no ano de 1839, durou, em sua primeira fase até 1847, falindo em virtude de problemas administrativos, ausência de subsídio e contexto econômico desfavorável. Empresários brasileiros compraram a companhia, renomeando-a para Companhia Bonfim (SAMPAIO, 2006). A Companhia Bahiana, contudo, ressurgiu em 1858, resultado da fusão entre as Companhias Bonfim e Santa 
Cruz, que exploraram o serviço da navegação a vapor concomitantemente entre os anos de 1852 e 1858. Enquanto a Companhia Bonfim prestava o serviço da navegação interna desde 1847, atendendo as localidades do Recôncavo baiano, a Empresa Santa Cruz foi criada, alguns anos depois, com o objetivo de prestar o serviço na navegação costeira, inclusive extrapolando os limites territoriais da Província da Bahia, alcançando os portos de Sergipe e Alagoas. Empresa mais vigorosa e com maior volume de capitais, a Santa Cruz recebia incentivos do governo imperial para realizar o serviço, devido aos objetivos de maior integração territorial do Império brasileiro (SAMPAIO, 2006, SAMPAIO, 2008).

A Companhia Bonfim não resistiu à falta de recursos e a conjuntura de crise econômica que afligia a Província da Bahia, principalmente em função da epidemia de cóleramorbo e da forte seca que atingiram a região nesse período. A Companhia Santa Cruz, por sua vez, também sofreu as agruras do período de seca que atingiu também as economias de Sergipe e Alagoas, prejudicando o desempenho do tráfego. O outro trecho servido pela companhia atendia às localidades do sul da Província, cujas economias ainda eram mais incipientes, com baixo dinamismo econômico, o que se refletia sobre o desempenho do transporte de mercadorias e passageiros.

A necessidade de formação de uma companhia mais robusta para enfrentar os desafios prementes da economia baiana conduziu à fusão das duas empresas e a incorporação de novos acionistas, renascendo a Companhia Bahiana em 1858. Poucos anos depois, porém, em 1862, os ingleses adquiriram a maior parte das ações da empresa, tornando-a uma companhia britânica que recebeu o nome de Bahia Steam Navigation Company (SAMPAIO, 2006).

Desde a abolição do tráfico de escravos, conforme mencionado anteriormente, que os ingleses estreitaram os laços econômicos com o Brasil, expandindo sua atuação na economia nacional. Castro (1978, p. 32) afirmou que entre 1860 e 1875, 94\% de todo o capital externo investido no Brasil era de origem inglesa. O ambiente mais favorável, tanto do ponto de vista político, quanto do ponto de vista econômico, provocaram essa expressiva ampliação da presença britânica na economia brasileira em geral. Não há estranhamento, portanto, que neste momento, os ingleses retornassem ao controle da Companhia Bahiana, uma empresa de navegação a vapor regional de atuação importante dentro do projeto de integração territorial do país. O aporte de capitais britânicos foi substancial, proporcionando à empresa vivenciar sua melhor fase, ampliando significativamente sua frota e expandindo seu raio de atuação.

Neste contexto, Hugh Wilson surge como uma figura destacada dentro da Companhia Bahiana, como o segundo maior investidor. O principal investidor da companhia foi um cidadão britânico chamado John Watson que investiu 239:215\$655 réis, seguido por Hugh 
Wilson, que investiu 6:929\$352 réis (SAMPAIO, 2006, p. 157). Nesta época, há evidências de que Wilson ainda residia na Inglaterra e que ocupava o cargo de secretário da empresa em Londres, como atesta Sampaio (2006, p. 163):

\begin{abstract}
Enquanto a companhia comemorava o sucesso da visita do superintendente ao imperador, os acionistas reclamavam do aumento crescente das despesas. Os diretores, então, designaram o secretário Hugh Wilson para viajar à Bahia com o objetivo de solucionar o problema e, assim, tranqüilizar os investidores.
\end{abstract}

O desempenho satisfatório na execução dessa tarefa contribuiu para a promoção de Hugh Wilson de secretário a superintendente da Companhia Bahiana em apenas quatro meses. Na função de superintendente, exerceu papel de destaque na expansão dos serviços da empresa para novas localidades da Província da Bahia, além de empreitadas mais ambiciosas como a navegação a vapor no rio São Francisco e na Província de Alagoas (SAMPAIO, 2006).

Hugh Wilson conseguiu um empréstimo do Banco da Bahia, da ordem de 160:000\$000 réis para implantação da navegação a vapor no rio São Francisco e nas lagoas do Norte e Manguaba na Província de Alagoas. Recursos que seriam pagos com a subvenção da navegação costeira (SAMPAIO, 2006, p. 184). Em correspondência enviada ao Presidente da Província da Bahia, Barão de São Lourenço, no ano de 1869 e, apresentada por este em seu relatório anual, Wilson menciona que a Companhia Bahiana era a única estrangeira neste ramo no Império do Brasil ${ }^{4}$ :

\begin{abstract}
Esta empresa, Exm $^{\circ}$ Sr., tem passado, desde seu princípio, por diferentes phases, e hoje é a única Companhia estrangeira de navegação a vapor que existe no Império: sua posição, me parece, não é secundária a qualquer outra; e posso afirmar que se continuar a ser bem dirigida o seu futuro se apresentará muito brilhante; e é para esse fim que tenho dedicado todas as minhas fracas forças, coadjuvando-me sempre com muita vontade todos os mais empregados desta Companhia; tendo em vista que a sua prosperidade só atingirá conciliando os seus interesses com os do Governo e os do Commercio em geral.
\end{abstract}

Outra conquista importante de Hugh Wilson enquanto superintendente da Companhia Bahiana foi implementar a linha do litoral da cidade de Salvador. O processo de transformação urbana que a capital da Província experimentava após a abolição do tráfico de escravos dinamizou a economia citadina, amplificando as demandas por modernização no sistema de transportes urbanos. A implementação da 1 ${ }^{\text {a }}$ Secção da Estrada de Ferro da Bahia ao Rio São Francisco e da linha litorânea da navegação a vapor pela Companhia Bahiana

\footnotetext{
${ }^{4}$ Relatório apresentado pelo Pres. da Província da Bahia Barão de São Lourenço n’ Abertura da Assembléa Legislativa da mesma província em 1869.
} 
atendiam, ainda que parcialmente, à demanda da sociedade soteropolitana. A linha litorânea, no entanto, enfrentou dificuldades que inviabilizaram a sua continuidade, extinguindo-se poucos anos após sua inauguração (SAMPAIO, 2006, p. 206).

Hugh Wilson deixou o cargo de superintendente da Companhia Bahiana no final do ano de 1869, sendo substituído por John Guillermo Illius, que era um dos diretores da companhia em Londres (SAMPAIO, 2006, p. 199). O legado de Wilson na superintendência da Companhia Bahiana revela sua importância no projeto de expansão e modernização da mesma. Durante sua gestão, a empresa saltou de 12 para 20 embarcações, ampliou seus serviços para a navegação no rio São Francisco e nas lagoas Norte e Manguaba na Província de Alagoas, implantou a linha do litoral da cidade de Salvador e expandiu o número de localidades atendidas na Bahia. A despeito dos problemas enfrentados e da expansão exagerada da companhia, foi, sem dúvida, seu melhor período, se constituindo em sua fase áurea (SAMPAIO, 2006). Wilson saiu da Companhia Bahiana, mas não da Província da Bahia, uma vez que, poucos anos depois, investiu em ferrovias e nos trilhos urbanos.

\section{A atuação de Hugh Wilson no segmento ferroviário e nos transportes urbanos}

No início da década de 1870, Hugh Wilson entrou no ramo das ferrovias ao adquirir a massa falida da empresa 'Paraguassu Steam Tram-Road', assumindo a concessão para construir uma estrada de ferro ligando a freguesia de São Félix até a Chapada Diamantina, atingindo o sertão baiano, além de uma ponte entre Cachoeira e São Félix e um ramal ferroviário entre Cachoeira e a vila de Feira de Santana, que começava a prosperar. Essa concessão havia sido originalmente adquirida pela referida empresa em 1865 (MATTOSO, 1992, p.471).

Esses projetos eram vitais para o desenvolvimento da Província, pois o governo entendia ser essencial a conexão entre o sertão e o litoral. O escoamento da produção agrícola seria beneficiado proporcionando um ponto de integração entre várias regiões da Província. De um lado mercadorias seguiriam para a Chapada, alcançando o sertão, do outro atingiriam a florescente vila de Feira de Santana. A ponte uniria esses dois trechos, dinamizando o tráfego de passageiros e mercadorias. Percebe-se, portanto, que este era um empreendimento de extrema importância para uma das províncias mais destacadas do Império como argumenta Moreira (2002, p. 77):

${ }^{5}$ FALLA que recitou o Pres. da Província da Bahia Antônio Cândido da Cruz Machado n’ Abertura da Assembléa Legislativa da mesma província em 1874. 
A construção da Estrada de Ferro Central da Bahia, partindo de São Félix a linha principal, e de Cachoeira seu ramal que deveria atingir Feira de Santana, está de acordo com o projeto imperial de “encurtar distâncias”, acelerando as comunicações entre as regiões mais importantes do Império.

Apesar de toda esta importância, a primeira tentativa de realizar tal empreitada não obteve sucesso. Hugh Wilson, que era um dos acionistas da falida empresa, demonstrou interesse em adquiri-la e realizar os projetos. Para se ter uma idéia da dificuldade de realizar tais empreendimentos, de um total de 30 concessões fornecidas pelo governo provincial entre 1852 e 1893, 15 fracassaram (MATTOSO, 1992, p.470).

Quando Wilson assinou o contrato em 26 de setembro de 1872, ficou acordado que a prioridade seria fazer o ramal entre Cachoeira e Feira de Santana e a ponte entre Cachoeira e São Félix. Posteriormente, implementaria a Estrada de Ferro Central da Bahia, que foi o nome dado à empresa. No contrato, ficou estipulado que a Província faria um empréstimo 1400 contos de réis, sendo 300 contos inicialmente e mais 200 anualmente, restando apenas 100 no último ano, conforme informou o Presidente Cruz Machado. Ao concretizar a transação, Wilson não demorou a receber a primeira parcela do empréstimo, tendo sido realizado o pagamento de 300 contos de réis por parte da Província no dia 11 de outubro de 1872, fato relatado no mesmo ano pelo então Presidente da Província Joaquim Pires Machado Portella ${ }^{6}$. Uma evidência da importância desse capitalista e do projeto pode ser constatada pela declaração do Presidente da Província Antonio Cândido da Cruz Machado, que cita o empreendimento ao justificar a documentação exigida a Wilson para levar adiante o projeto:

\footnotetext{
Por mais crédito que mereça individualmente e como negociante o empresario citado, não pode a província dispensar aquellas formalidades que constituem a garantia das concessões feitas. Esta empresa, uma das de maior vulto da província, quer pelos resultados que deve produzir desde já, quer pelos prometidos no futuro, merece toda attenção e solicitude de V. Ex. [...]
}

Segundo Cruz Machado, ao iniciar os trabalhos, Wilson planejava finalizar o ramal de Feira de Santana até maio de 1874. Não conseguiu, entretanto, realizar o projeto no prazo previsto, pois enfrentou muitas dificuldades, especialmente para levantar os capitais necessários para custear as obras, devido à escassez de capitais no mercado londrino, fruto das incertezas vividas na Europa com ameaças de guerra. Desta forma, os trabalhos de Wilson foram bastante prejudicados, restando a ele recorrer à Província, em julho de 1876, um

\footnotetext{
${ }^{6}$ Relatório com que o Pres. Da Província da Bahia Joaquim Pires Machado Portella passou a Administração da mesma ao $1^{\circ}$ Vice-Presidente João José de Almeida Couto no dia 16 de Novembro de 1872.
} 
adiantamento do valor do empréstimo previsto para receber em setembro daquele mesmo ano, o que foi concedido pelo Presidente da Província Henrique Pereira de Lucena:

\begin{abstract}
Attendendo a todas estas considerações e principalmente ao interesse da província, a primeira a soffrer qualquer prejuiso que resulte do estado precario ou máo em que possa vir a achar-se a empreza, e attendendo tambem ao máo effeito que produzirião em Londres quaesquer noticias desanimadoras de paralysação das obras e descrédito da mesma empreza, não hesitei em annuir o favor sollicitado, de adiantar desde logo 50:000\$000, dos 200:000\$000rs. que em Setembro tinhão de ser entregues.
\end{abstract}

Com esse adiantamento parcial ele conseguiu terminar o trecho que faltava para que a viagem no ramal de Feira de Santana fosse feito de maneira contínua. Desse modo, em 02 de dezembro de 1876 foi inaugurada a linha férrea de Cachoeira até Feira de Santana. Tal obra representou um grande avanço na junção entre regiões importantes e foi o início do grande progresso da vila de Feira de Santana, que esteve assim mais próxima da capital da Província. Ressalta o então presidente Henrique Pereira de Lucena em 1877 :

Póde hoje o habitante da Feira de Sant`Anna chegar à capital no mesmo dia em que sahe de casa, realisar quasquer negocios e operações, voltando para a Cachoeira no mesmo dia, e no seguinte para a Feira.

Informa ainda este presidente que mesmo com a via férrea pronta, ainda faltavam as estações nos dois terminais, sem as quais o engenheiro fiscal da Província não poderia aceitar a linha, como estava previsto no decreto n. 5777 de 28 de outubro de 1874. Sem recursos, Wilson propôs um novo adiantamento ao governo da Província, que não concordou. A solução encontrada foi um empréstimo fornecido pelo Banco Mercantil de cem contos de réis, que seria quitado pela Província em setembro de 1877. Wilson, desse modo, conseguiu terminar as estações para que o ramal fosse aceito e gozar da garantia de 7\% de juros pelo capital despendido, prevista no contrato. Esta solução foi crucial para o sucesso deste empreendimento, mencionado pelo Presidente da Província Antônio de Araújo Bulcão na abertura da Assembléia Legislativa da Bahia em $1879^{\circ}$. Segundo este presidente, com as duas estações prontas o movimento de pessoas e mercadorias na linha cresceu satisfatoriamente, auspiciando um grande futuro para os projetos de Wilson.

A ponte, por sua vez, demorou mais tempo para sair do papel. Sua construção era fundamental para dinamizar as relações entre Cachoeira e São Félix, cuja viagem era feito por

\footnotetext{
${ }^{7}$ FALLA que recitou o Pres. da Província da Bahia Henriq ue Pereira de Lucena n’ Abertura da Assembléa Legislativa da mesma província em 1877.

${ }^{8}$ FALLA que recitou o Pres. da Província da Bahia Antônio de Araújo Bulcão n’ Abertura da Assembléa Legislativa da mesma província em 1879.
} 
barcos. Este era, na verdade, um antigo desejo dos moradores da região, como ressalta Moreira (2002, p. 56):

A partir da $1^{\text {a }}$ década do século XIX, os requerimentos para construção de uma ponte que ligasse as 2 localidades não só aumentaram, como tornaram-se mais incisivos $[\ldots]$

Mesmo com essa precoce ambição da sociedade local, a ponte só ficou pronta no final do século XIX. Quando Wilson assumiu o projeto, havia uma grande discussão sobre o local exato para sua construção, tendo ele conseguido a autorização do governo em 01 de junho de 1874 para mudar o local. Entretanto apenas em 22 de dezembro de 1880 foi posta a pedra inaugural no local denominado Manga. Sobre isto celebra o então Presidente da Província, João Lustosa da Cunha Paranaguá9:

Em breve se dará principio á construcção da mesma ponte, que é de incalculavel vantagem para o commercio das duas povoações situadas á margem do Paraguassú, e para o commercio e lavoura do centro da Provincia.

A ponte foi inaugurada em 07 de julho de 1885, recebendo o nome de Imperial Dom Pedro II, fazendo então a conexão entre Feira de Santana e a ferrovia que seguia para a Chapada, conforme informou o Conselheiro Theodoro Pereira da Silva em $1886^{10}$. A linha principal da Estrada de Ferro Central da Bahia colocou à prova, a capacidade de Hugh Wilson empreender. Após lutar para conseguir investidores em Londres, onde a empresa recebeu o nome de 'Railway Brazilian Imperial Central Company Limited', em 11 de setembro de 1877, o empresário mandou informar ao governo provincial que havia conseguido levantar os capitais necessários para prosseguir com as obras, como relatou o Presidente da Província Barão Homem de Mello em $1878^{11}$. A primeira cota do seu capital era da ordem de 4.231:161\$00 e, pelo decreto n. 2637 de 31 de julho de 1877, a empresa fez as encomendas dos materiais para a estrada de ferro até a chapada, de acordo com Presidente da Província Antonio de Araújo Aragão Bulcão ${ }^{12}$.

Somente em 17 de maio de 1879, no entanto, o governo aprovou as plantas da estrada até o km104, baseado nos estudos feitos pelo próprio Wilson. Os trabalhos começaram então no mesmo dia, seguindo a direção do Vale do Capivary. A empreitada desenvolveu-se bem, se

\footnotetext{
${ }^{9}$ FALLA que recitou o Pres. da Província da Bahia João Lustosa da Cunha Paranaguá n’ Abertura da Assembléa Legislativa da mesma província em 1881.

${ }^{10}$ FALLA que recitou o Conselheiro Theodoro Machado Freire Pereira da Silva n’ Abertura da Assembléa Legislativa da mesma província em 1886

${ }^{11}$ Relatório com que o Pres. Da Província da Bahia Barão Homem de Mello passou a Administração da mesma ao $2^{\circ}$ Vice-Presidente Antonio de Araújo Bulcão no dia 25 de Novembro de 1878.

${ }^{12}$ FALLA que recitou o Pres. da Província da Bahia Antônio de Araújo Bulcão n’ Abertura da Assembléa Legislativa da mesma província em 1879.
} 
destacando como fonte geradora de empregos na região, como salienta o mesmo Araújo Bulcão em seu discurso no ano seguinte ${ }^{13}$ :

Os trabalhos têm tido regular andamento, sendo para esperar que até o fim d'este anno estejão promptos 65 kilometros até o Curralinho. N`estas obras são empregados cerca de 2.000 trabalhadores, a maior parte nacionaes.

O primeiro trecho da estrada foi inaugurado em 22 de dezembro de 1880 e ia de São Félix até Tapera, com uma extensão de $84 \mathrm{~km}$. Hugh Wilson continuou fazendo os estudos para a linha que previa um total de 257 quilômetros, chegando ao município de João Amaro, o que prometia bons lucros:

Aos esforços e actividade do infatigável Engenheiro Civil Hugh Wilson é devido em grande parte o progresso que tem tido a construcção da Estrada de Ferro Central, que promette auspicioso futuro ás localidades por onde ella passa, ás adjacentes e ás dos nossos sertões, logo que chegue a João Amaro. ${ }^{14}$

Em 1887, a linha já contava com 299 km e o ponto terminal era a Estação Bandeira de Mello, o que foi importantíssimo para facilitar as comunicações do sertão com a capital (CALMON, 1979). Outro empreendimento do empresário Hugh Wilson foi a empresa Trilhos Urbanos de Cachoeira, que operava dentro a cidade de mesmo nome. Além de ser a segunda cidade mais importante da Província à época, o que justificava o investimento em um sistema viário urbano, ele planejou essa linha para servir como complementar à Estrada de Ferro Central da Bahia. Sendo assim, essa linha iniciava na estação de Cachoeira do ramal de Feira de Santana e terminava na ponte Imperial D. Pedro II, fazendo a junção com os outros empreendimentos também gerenciados por Wilson. Isso evidencia a visão empresarial dele, que esteve envolvido em alguns dos principais projetos de modernização da Província.

Hugh Wilson também participou como sócio-gerente de outra empresa de trilhos urbanos, a de Santo Amaro, localidade que se destacava, conforme visto, como um dos principais entrepostos comerciais das mercadorias da Província da Bahia. Esta empresa começou a funcionar em 01 de janeiro de $1874^{15}$. Hugh Wilson ambicionava ampliar as relações comerciais entre as principais localidades do recôncavo com a capital, bem como estabelecer um sistema de interligação entre essas localidades e o sertão. A idéia de montar

\footnotetext{
${ }^{13}$ FALLA que recitou o Pres. da Província da Bahia Antônio de Araújo Bulcão n’ Abertura da Assembléa Legislativa da mesma província em 1880.

${ }^{14}$ FALLA que recitou o Pres. da Província da Bahia João Lustosa da Cunha Paranaguá n’ Abertura da Assembléa Legislativa da mesma província em 1881.

${ }^{15}$ FALLA que recitou o Pres. da Província da Bahia Antônio Cândido da Cruz Machado n’ Abertura da Assembléa Legislativa da mesma província em 1874.
} 
um sistema interligado em Santo Amaro, assim como fez na cidade de Cachoeira, o levou ao projeto da Estrada de Ferro Santo Amaro.

Este projeto surgiu por volta de 1870, quando o governo provincial outorgou a concessão para que fosse construída a linha, sob o nome de Animação Industrial. A estrada iniciaria em Santo Amaro e seguiria até o local denominado Bom Jardim. Essa linha era de grande importância, pois atravessaria zonas férteis e produtivas, em que se plantavam café, fumo, cana-de-açúcar e cereais.

A concessão da estrada esteve nas mãos de alguns particulares até chegar ao Visconde de Sergimirim, que encarregou Hugh Wilson de realizar os estudos para montar a companhia que se encarregaria da operação desse projeto. O próprio Wilson, posteriormente, assumiu a concessão e chegou a ver suas plantas aprovadas pela Província; o projeto, no entanto, não saiu do papel por falta de capitais. Neste sentido, relatou o Presidente da Província Henrique Pereira de Lucena em 01 de janeiro de $1877^{16}$ :

Não podendo conseguir levantar capitaes no Imperio, espera o actual emprezario Hugh Wilson conseguil-o, uma vez que entre em effectividade de operações a companhia da estrada de ferro central.

A ideia de Wilson era financiar a construção dessa ferrovia com os lucros da Estrada Central, mas devido ao próprio atraso das obras do seu principal empreendimento, ele não teve como realizar a Estrada de Ferro Santo Amaro. O governo provincial então realizou a construção da ferrovia, que entrou em funcionamento em 1879 (CARLETTO,1979, P.23). Hugh Wilson não desistiu da idéia de assumir essa via férrea e em 1881 quando o governo provincial manifestou o interesse de se desfazer da Estrada de Ferro de Santo Amaro ele foi um dos interessados. Todavia a sua proposta não foi aceita, uma vez que não se adequava às exigências da Província. Certamente o interesse de Wilson pela empresa aumentou quando, segundo Mattoso (1992, p. 184):

Em 1880 os Costa Pinto fundaram a usina de Bom Jardim, primeira usina central de açúcar da Bahia e a segunda do Brasil, e foram pioneiros na introdução de técnicas agrícolas modernas.

A região, que já prometia bons lucros, ganhou um novo estímulo ao desenvolvimento por meio do empreendimento inovador trazido por uma tradicional família baiana. Mesmo gozando de status na Província devido a todo o seu empenho na realização dos projetos, Wilson não conseguiu persuadir o governo provincial a lhe vender a empresa e assim efetuar a

\footnotetext{
${ }^{16}$ FALLA que recitou o Pres. da Província da Bahia Henrique Pereira de Lucena n’ Abertura da Assembléa Legislativa da mesma província em 1877.
} 
junção com a Trilhos Urbanos de Santo Amaro, a exemplo do que ele havia feito em Cachoeira $^{17}$.

Apesar do resultado insatisfatório nesta empreitada, não há dúvidas de que Hugh Wilson teve um papel fundamental para o desenvolvimento e modernização do sistema de transportes da Província da Bahia na segunda metade do século XIX. Ele representava algo que não existia no seio da sociedade baiana, conforme escreveu MATTOSO (1992, p. 470):

Investimentos de médio e longo prazos, mesmo com juros garantidos, provavelmente não seduziam o investidor baiano, habituado a práticas altamente especulativas.

Uma afirmação do Conselheiro Pedro Luiz Pereira de Sousa se referindo à empresa Trilhos Urbanos de Santo Amaro na fala de abertura da assembleia provincial em 03 de abril de $1883^{18}$ demonstra o status que gozava Wilson: “Esta empreza, que é dirigida pelo digno commendador Hugh Wilson, funcciona com regularidade”. Evidentemente não era qualquer cidadão que recebia o título de comendador, especialmente um estrangeiro, o que demonstra o reconhecimento por parte da Província pelos serviços prestados por este cidadão britânico.

A história do engenheiro e capitalista britânico Hugh Wilson revela aspectos importantes sobre o papel destacado dos investimentos ingleses no processo de modernização da estrutura produtiva baiana e brasileira. A postura de empreendedor ativo, com uma visão vanguardista, fruto da influência da mentalidade industrialista britânica, confrontava com a significativa postura arcaica das elites locais, defensoras dos seus interesses de preservação do modelo primário-exportador e de seu papel dominante na sociedade brasileira. Por outro lado, o capitalista Hugh Wilson se dedicou a um projeto modernizante em consonância com os interesses da sociedade nativa, atrelada ao passado, de modelo aristocrático, rural e patrimonialista. Os setores que se modernizaram, tornavam a economia baiana mais eficiente em termos de infra-estrutura, mas ela continuava sendo agrária, enquanto a industrialização alavancava outras economias pelo mundo. A modernização veio, portanto, apenas para reforçar o quadro socioeconômico vigente, não para transformá-lo.

\section{Considerações finais}

A participação do engenheiro e capitalista inglês Hugh Wilson em diversos empreendimentos ligados ao setor de transportes da Bahia oitocentista desvela um quadro de

\footnotetext{
${ }^{17}$ FALLA que recitou o Pres. da Província da Bahia João Lustosa da Cunha Paranaguá n’ Abertura da Assembléa Legislativa da mesma província em 1881.

${ }^{18}$ FALLA que recitou o Pres. da Província da Bahia Pedro Luiz Pereira de Souza n’ Abertura da Assembléa Legislativa da mesma província em 1883.
} 
atuação dos capitais britânicos em economias periféricas, como a brasileira e, particularmente, a baiana. Diversos autores e pesquisadores que se debruçaram sobre a história econômica do Brasil ou mesmo mundial, mais detidamente no estudo sobre a dinâmica das relações econômicas internacionais no século XIX, constataram um padrão de investimentos dos países centrais, em sua maioria de origem inglesa, em áreas periféricas do sistema internacional.

A alocação de capitais destinava-se prioritariamente ao setor de serviços, destacandose bancos, comunicações, transportes e seguros. Segmentos da atividade econômica que cumpriam uma dupla função dentro do sistema internacional de poder político e econômico: amplificação dos destinos dos capitais e preservação da divisão internacional do trabalho na dicotomia entre economias centrais (industrializadas) e economias periféricas (agroexportadoras). O sistema bancário solidificava as bases de expansão dos capitais externos, principalmente a partir da principal praça financeira do período que era Londres. Os segmentos de comunicações e transportes tornavam mais eficientes e céleres as transações comerciais internacionais, proporcionando ampliação do volume de negócios e redução de custos para os produtores e comerciantes. O setor de seguros, por sua vez, reforçava esse sistema por meio da redução dos riscos para as relações mercantis em escala mundial, tornando o ambiente ainda mais favorável para a expansão dos mercados.

A história da presença do capitalista e engenheiro inglês Hugh Wilson em terras baianas, portanto, está inserida neste ambiente mais amplo, fortalecendo-o em sua essência. De acionista e ocupante de um dos cargos de maior destaque dentro da Companhia Bahiana de Navegação a Vapor a empreendedor de projetos de ferrovias e companhias de trilhos urbanos, sua área de atuação sempre esteve atrelada ao setor de transportes. Não há dúvida quanto ao seu papel importante na transformação modernizadora que o segmento dos transportes vivenciou na Bahia do oitocentos, seja por meio da expansão da navegação a vapor ou pela ampliação dos transportes terrestres, destacando-se as ferrovias, notadamente, ramo em que empreendeu seus maiores esforços.

A característica de empreendedor vanguardista, sintonizado com as mudanças tecnológicas a partir da Grã-Bretanha, nação hegemônica no sistema internacional, contrastava com o conservadorismo presente no seio da sociedade baiana, de fidalgos e comerciantes. A busca pela agilidade nas transações comerciais e o discurso em defesa do progresso, conflitava com a letargia e resistência do ambiente interno. O projeto modernizador somente foi aceito e incorporado ao universo local, por sua evidente 
contribuição para melhorar as relações mercantis regionais, sem promover a transformação estrutural mais importante, do modelo no qual se assentava a economia baiana.

A participação de Hugh Wilson nas transmudações da economia baiana no decurso da segunda metade do oitocentos se confunde com a história da modernização conservadora que a Província da Bahia vivenciou. A navegação a vapor e as ferrovias encurtaram distâncias e recrudesceram as relações comerciais intraprovinciais e interprovinciais, bem como expandiram o comércio exterior. Os trilhos urbanos trouxeram um elemento modernizador ao momento de profundas transformações que o ambiente citadino experimentava, com ampliação do setor bancário, comercial, melhoria da iluminação pública, instalação do telégrafo, dentre outros. A Província da Bahia se modernizava e conservava, ao mesmo tempo, sua estrutura econômica e de poder, e o cidadão inglês Hugh Wilson fazia parte dessa história, desempenhando um papel importante.

\section{Referências}

Fontes manuscritas e impressas

Arquivo Público do Estado da Bahia (APEB)

Fallas, mensagens e relatórios de Presidentes da Província

\begin{tabular}{|l|l|l|}
\hline Presidente & Ano & Documento \\
\hline José Augusto Chaves & 1862 & Relatório \\
\hline Joaquim Antão F. Leão & 1862 & Falla \\
\hline Joaquim Antão F. Leão & 1862 & Relatório \\
\hline Antônio C. Sá e Albuquerque & 1862 & Falla \\
\hline Antônio C. Sá e Albuquerque & 1863 & Falla \\
\hline Antônio C. Sá e Albuquerque & 1863 & Relatório \\
\hline Manuel Maria do Amaral & 1864 & Falla \\
\hline Antônio Joaquim Gomes & 1864 & Relatório \\
\hline Luiz Antônio B. de Almeida & 1865 & Relatório \\
\hline Manuel Pinto de S. Dantas & 1866 & Relatório \\
\hline Pedro Leão Velloso & 1866 & Relatório \\
\hline Ambrósio Leitão da Cunha & 1867 & Relatório \\
\hline José Bonifácio Azambuja & 1868 & Relatório \\
\hline Barão de São Lourenço & 1869 & Relatório \\
\hline Barão de São Lourenço & 1870 & Relatório \\
\hline Barão de São Lourenço & 1871 & Relatório \\
\hline
\end{tabular}




\begin{tabular}{|c|c|c|}
\hline João José de Almeida Couto & 1871 & Relatório \\
\hline João Antônio de Araújo F. Henriques & 1872 & Falla \\
\hline João José de Almeida Couto & 1872 & Relatório \\
\hline João José de Almeida Couto & 1873 & Falla \\
\hline José Eduardo F. Carvalho & 1873 & Relatório \\
\hline Venâncio José de Oliveira Lisboa & 1874 & Relatório \\
\hline Antônio Cândido da Cruz Machado & 1874 & Falla \\
\hline Venâncio José de Oliveira Lisboa & 1875 & Relatório \\
\hline Luiz Antônio da Silva Nunes & 1876 & Relatório \\
\hline Luiz Antônio da Silva Nunes & 1876 & Relatório \\
\hline Henrique Pereira de Lucena & 1877 & Falla \\
\hline Henrique Pereira de Lucena & 1877 & Relatório \\
\hline Ignácio José Ferreira & 1878 & Relatório \\
\hline Barão Homem de Mello & 1878 & Falla \\
\hline Antônio de Araújo Bulcão & 1879 & Falla \\
\hline Antônio de Araújo Bulcão & 1880 & Falla \\
\hline Lustosa da Cunha Paranaguá & 1881 & Falla \\
\hline Lustosa da Cunha Paranaguá & 1882 & Relatório \\
\hline João dos Reis de Souza Dantas & 1882 & Relatório \\
\hline Pedro Luiz Pereira de Souza & 1883 & Falla \\
\hline Pedro Luiz Pereira de Souza & 1884 & Falla \\
\hline João Rodrigues Chaves & 1884 & Relatório \\
\hline Espiridião Eloy de Barros Pimentel & 1885 & Falla \\
\hline Theodoro Machado Freire Silva & 1886 & Falla \\
\hline João Capistrano B. de Mello & 1887 & Falla \\
\hline Manoel do N. M. Portella & 1888 & Falla \\
\hline Aurélio Ferreira Espinheira & 1889 & Falla \\
\hline
\end{tabular}

\section{Seção Colonial e Provincial}

\begin{tabular}{|l|l|l|l|}
\hline Maço & Série & Documento & Período \\
\hline 3180 & Polícia do Porto & Vapor Presidente Dantas & $1866-1872$ \\
\hline 5030 & $\begin{array}{l}\text { Viação: transportes } \\
\text { fluviais e marítimos }\end{array}$ & $\begin{array}{l}\text { Steam Nav. Co. Royal } \\
\text { Mail Steam }\end{array}$ & 1874 \\
\hline 5031 & $\begin{array}{l}\text { Viação: transportes } \\
\text { fluviais e marítimos }\end{array}$ & $\begin{array}{l}\text { Cia. Navegação } \\
\text { Transatlântica }\end{array}$ & 1886 \\
\hline 5032 & $\begin{array}{l}\text { Viação: transportes } \\
\text { fluviais e marítimos }\end{array}$ & $\begin{array}{l}\text { Emp. } \\
\text { Jequitinhonha }\end{array}$ & $1852-1877$ \\
\hline
\end{tabular}




\begin{tabular}{|l|l|l|l|}
\hline 5033 & $\begin{array}{l}\text { Viação: transportes } \\
\text { fluviais e marítimos }\end{array}$ & $\begin{array}{l}\text { Cia. Navegação Ponta de } \\
\text { Areia }\end{array}$ & 1867 \\
\hline $5038-5041$ & $\begin{array}{l}\text { Viação: transportes } \\
\text { fluviais e marítimos }\end{array}$ & $\begin{array}{l}\text { Cia. Brasileira de } \\
\text { Navegação a Vapor }\end{array}$ & $1847-1888$ \\
\hline 5044 & $\begin{array}{l}\text { Viação: transportes } \\
\text { fluviais e marítimos }\end{array}$ & $\begin{array}{l}\text { Cia. Navegação Europa- } \\
\text { Americana }\end{array}$ & 1857 \\
\hline $\begin{array}{l}4998-1 \\
5012\end{array}$ & Viação & $\begin{array}{l}\text { Transportes urbanos } \\
\text { (diversos) }\end{array}$ & $1869-1888$ \\
\hline 5037 & Viação & $\begin{array}{l}\text { Cia. Navegação Charles } \\
\text { Vignoles }\end{array}$ & 1856 \\
\hline
\end{tabular}

\section{Bibliografia}

ABREU, Maurício de Paiva. British Business in Brazil: maturity and demise (1850-1950). Rio de Janeiro: Revista Brasileira de Economia, Out./ Dez., 2000.

ALMEIDA, Rômulo. Traços da História Econômica da Bahia no Último Século e Meio. Salvador: Revista de Economia e Finanças, 1951. (Textos sobre Economia Baiana).

ARRIGHI, Giovanni. O longo século XX. 5 ed., São Paulo: Contraponto, 2006.

CALMON, Francisco Marques de Góes. Vida Econômico-Financeira da Bahia de 1808 a 1899. Salvador: Fundação de Pesquisa/CPE, SEPLANTEC, 1979.

CASTRO, Ana Célia. As Empresas Estrangeiras no Brasil (1860-1913). 1 1a ed., Rio de Janeiro: Zahar, 1978.

CHANG, Ha-Joon. Chutando a escada: a estratégia do desenvolvimento em perspectiva histórica. São Paulo: UNESP, 2004.

EL-KAREH, Almir Chaiban. A Companhia Brasileira de Paquetes a Vapor e a Centralidade do Poder Monárquico. São Paulo: Revista História Econômica \& História de Empresas/ ABPHE, vol. V, n ${ }^{\circ} 2,2002$.

FREYRE, Gilberto. Ingleses no Brasil - aspectos da influência britânica sobre a vida, a paisagem e a cultura do Brasil. São Paulo: José Olympio, 1948. (Col. Documentos Brasileiros).

FURTADO, Celso. Formação Econômica do Brasil. 16 a ed., São Paulo: Cia. Editora Nacional, 1979.

GRAHAM, Richard. Grã-Bretanha e o Início da Modernização no Brasil (1850-1914). São Paulo: Brasiliense, 1973. (Trad. Roberto Machado de Almeida). 
HOBSBAWM, Eric J. Da Revolução Industrial Inglesa ao Imperialismo. 4 ${ }^{\text {a }}$ ed., Rio de Janeiro: Forense-Universitária, 1986. (Trad. Donaldson Magalhães Garschagen).

MATTOSO, Kátia M. de Queirós. Bahia: a cidade do Salvador e seu mercado no século XIX. $1^{\text {a }}$ ed., São Paulo: Hucitec, 1978.

1992.

Bahia, século XIX: uma província no Império. Rio de Janeiro: Nova Fronteira,

PEDRÃO, Fernando. O Recôncavo Baiano na Origem da Indústria de Transformação no Brasil. Salvador: Revista do Instituto Geográfico e Histórico da Bahia, nº 92, 1996.

$17 / 04 / 2000$.

A Bahia na Formação da Economia Brasileira. In: Jornal A TARDE de 500 anos de comércio na Bahia, relatório elaborado para a Secretaria de Indústria e Comércio da Bahia, Salvador, 2000.

SAMPAIO, Marcos Guedes Vaz. Formação de um setor metalúrgico na Província da Bahia oitocentista: a presença britânica. Salvador: Revista de Desenvolvimento Econômico (RDE), n. 7 , ano IV, dezembro de 2002.

PRADO Jr., Caio. História Econômica do Brasil. 34ª ed., São Paulo: Brasiliense, 1986.

1981.

Formação do Brasil Contemporâneo (colônia). 17ª ed., São Paulo: Brasiliense,

SAMPAIO, Marcos Guedes Vaz. Uma contribuição à história dos transportes no Brasil: a Companhia Bahiana de Navegação a Vapor (1839-1894). 2006. 370 p. Tese (Doutorado em História Econômica) - Faculdade de Filosofia, Letras e Ciências Humanas, Universidade de São Paulo, 2006.

Navegação a vapor na Bahia oitocentista: tentativa de integração territorial e desenvolvimento regional. São Paulo: Revista de Economia Política e História Econômica, n. 14, agosto, 2008.

TAVARES, Luís Henrique Dias. História da Bahia. 10ª ed., São Paulo/Salvador: UNESP/EDUFBa, 2001. 